\title{
Musculoskeletal malignant neoplasms hospitalisation in Victoria
}

\author{
Timothy Ore* \\ Innovation Hub and Health System Improvement, Department of Health and Human Services, Melbourne, Australia
}

Received: June 16, 2015

Accepted: July 23, 2015

Online Published: July 27, 2015

DOI: $10.5430 /$ jer.v1n1p33

URL: http://dx.doi.org/10.5430/jer.v1n1p33

\begin{abstract}
The paper describes factors associated with 2,605 hospital admissions for musculoskeletal malignant neoplasms (MMN) over one year. The rates per 10,000 population increased significantly $(t=5.3, p<.01)$ with age, with men ( 4.5 per 10,000 population, $95 \%$ CI 4.1-5.0) at greater risk than women (3.3 per 10,000 population, 95\% CI 2.8-3.7). The 30-day readmission rate was 19\%, the third highest of all admission categories. The average length of stay was significantly $(t=4.5, p<.01)$ shorter in the metropolitan area (8.2 days) than in rural communities (10.8 days). The age-standardised rates varied inversely $(r=-0.28)$ with socioeconomic status. Communities with high MMN admission rates had high rates of heart failure admissions $(r=0.35)$, alcohol consumption $(r=0.34)$ and receiving Disability Support Pension $(r=0.32)$. There was a significant $(t=13.8, p<.001)$ monthly variability in MMN hospitalisation rates. As a leading cause of hospital readmission and disability, the condition requires closer analysis.
\end{abstract}

Key Words: Malignant neoplasms, Hospital readmission, Socioeconomic disadvantage, Musculoskeletal, Disability

\section{INTRODUCTION}

In developed countries, musculoskeletal conditions (MSC) are one of the leading causes of work absence and disability, representing $10 \%-20 \%$ of primary care consultations. ${ }^{[1,2]}$ MSC accounts for half of all sickness absences longer than two weeks in Norway and is the most expensive disease in Sweden ${ }^{[1]}$ and the United States. ${ }^{[3]}$ The direct cost of health service utilisation from MSC, as a percentage of gross national product, was $0.7 \%$ in the Netherlands, $1.0 \%$ in Canada and $1.2 \%$ in the United States. ${ }^{[1]}$

The purpose of this investigation is to explore the relationship between hospitalisation for musculoskeletal malignant neoplasms (MMN) and community socioeconomic status (SES). It is hypothesised that high SES communities have significantly lower age-adjusted MMN hospitalisation rates.
Also identified are demographic risk factors for MMN.

\section{MATERIALS AND METHODS}

\subsection{The setting}

Victoria is Australia's second largest state, accounting for a quarter (5.8 million) of its population. The state of Victoria comprises 79 Local Government Areas (LGA), of which 30 are in the metropolitan area (74.6\% of the population) and 49 are non-metropolitan ( $25.4 \%$ of the population).

Data on hospital admissions (the numerator) was taken from the Victorian Admitted Episodes Dataset (VAED), from 1 July 2013 to 30 June 2014. The VAED, maintained by the Department of Health and Human Services, contains morbidity data on all admitted patients to Victorian public and private acute hospitals, rehabilitation centres, extended care facilities

\footnotetext{
*Correspondence: Timothy Ore; Email: Timothy.Ore@dhhs.vic.gov.au; Address: Innovation Hub and Health System Improvement, Department of Health and Human Services, Level 20, 50 Lonsdale Street, Melbourne 3000, Australia.
} 
and day procedure centres. Also taken from the VAED were data on chronic obstructive pulmonary disease and renal failure. The denominator data was from the Australian Bureau of Statistics (ABS)' Estimated Resident Population.

SES was measured using the ABS Index of Relative Socioeconomic Disadvantage (IRSED). The index is derived from attributes including low income, low educational attainment, high unemployment and jobs in relatively unskilled occupations. The higher an area's IRSED, the less disadvantaged that area is compared with others. A high IRSED indicates that an area has few families of low income and few people with little training and in unskilled occupations.

Other data, including prevalence of alcohol, arthritis, obesity and cancer, were taken from the Victorian Population Health Survey (VPHS) 2011-12 to examine associations with MMN rates. Established in 1998, the VPHS is an annual survey of Victorians aged 18 years and over on a range of subjects, including health status, body mass index and presence of chronic diseases. Information is collected, via computer-assisted telephone interview, at state, regional and LGA levels. Data on Disability Support Pension (DSP), March 2014, was from the Commonwealth Department of Human Services.

\subsection{Statistical analysis}

Rates were calculated as the number of MMN admissions per 10,000 population, age-standardised using the direct method to the 2012 Victorian population. The data was analysed at the LGA level. The hypothesis was tested by computing Pearson product-moment correlation coefficients, with two-tailed significance tests. The coefficient is a measure of degree of linear dependence between two variables, but does not indicate causality. T-test was used to assess whether the means of relevant demographic groups were statistically different from each other. All statistical analyses were completed in SPSS, version 20.

\section{RESULTS}

There were 2,605 MMN admissions, 27.8\% to private hospitals and $72.2 \%$ to public hospitals. A third of the admissions had complications and comorbidities. MMN admissions per 10,000 population increased significantly $(t=5.3, p<.01)$ with age; men were at higher risk ( 4.5 per 10,000 population, $95 \%$ CI 4.1-5.0) than women (3.3 per 10,000 population, $95 \%$ CI 2.8-3.7). The risk differentials were marked in the older agegroups. The average length of stay was significantly shorter $(t=4.5, p<.01)$ in the metropolitan area (8.2 days) than in rural communities (10.8 days). The 30-day readmission rate was $19 \%$, the third highest of all admission categories. Twelve percent of the patients (323) died in hospital.
The MMN age-adjusted rates per 10,000 population varied inversely $(r=-0.28)$ with SES (see Figure 1). This shows that, in Victoria, people living in socioeconomically disadvantaged areas have significantly higher MMN hospitalisations. Table 1 presents the inter-correlation coefficients for several variables. Communities with high MMN hospitalisation rates had high rates of multiple conditions, including ageadjusted heart failure admissions ( $r=0.35$ ), alcohol consumption $(r=0.34)$, overweight and obesity $(r=0.23)$ and receiving $\operatorname{DSP}(r=0.32)$.

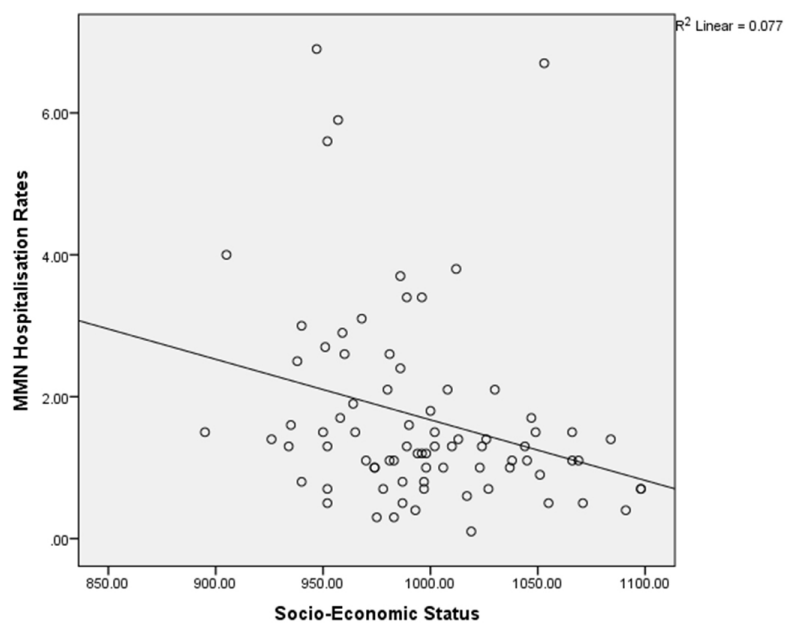

Figure 1. Association between musculoskeletal malignant neoplasms hospitalisation rates and socioeconomic status by Local Government Area

There was a statistically significant $(t=13.8, p<.001)$ monthly variability in MMN hospitalisation rates. The highest rate occurred in the month of January and the lowest in June.

\section{Discussion}

This analysis shows a significant negative correlation between community socioeconomic status and hospitalisation for musculoskeletal malignant neoplasms. The findings are broadly consistent with other studies. In what was probably the earliest investigation of the potential role of SES in osteoarthritis, Hannan et al. ${ }^{[4]}$ found that low educational attainment correlated with reporting more knee pain and arthritis. More recently, the Johnston County Osteoarthritis Project studies have strengthened this link. The Johnston County Project is an ongoing, longitudinal, population-based study of knee and hip osteoarthritis that includes both rural and urban communities in North Carolina. ${ }^{[5]}$ Callahan et al. ${ }^{[6]}$ have shown that both low levels of education and living in a community with a household poverty rate greater than $25 \%$ are independently associated with the risk for radiographic and symptomatic knee osteoarthritis. Cleveland et al. ${ }^{[5]}$ found

ISSN 2377-9306 E-ISSN 2377-9330 
that individuals with knee osteoarthritis who are at the highest risk of developing disability and pain have lower SES. Persons working in non-managerial occupations are more likely to have worse pain scores on the Western Ontario and McMaster Universities Index of Osteoarthritis compared to individuals in managerial positions. ${ }^{[5]}$ Among adults with knee and/or hip osteoarthritis, individual SES characteristics, including education level, ${ }^{[7]}$ occupation type ${ }^{[8]}$ and social class $^{[9]}$ are related to physical function and disability.

A combination of factors may explain the interaction between lower SES and elevated risk for MMN hospitalisation. As noted by Martin et al.,${ }^{[10]}$ communities with high poverty rates often have limited resources, including fewer clinics, public transportation options, community centres and safe places to exercise, all of which can improve health outcomes in individuals with osteoarthritis.

Occupations requiring strenuous physical movement, such as kneeling or heavy lifting, are associated with increased risk for knee or hip osteoarthritis. ${ }^{[11,12]}$ As Table 1 shows, the proportion of the population undertaking mostly heavy labour or physically demanding activity correlated significantly $(r=0.51)$, at the 1 per cent level, with MMN hospitalisation rates. Obesity is a risk factor for osteoarthritis of the hand, knee and hip, and Table 1 also indicates its influence on MMN $(r=0.23)$.

Table 1. Inter-correlation coefficients for age-standardised musculoskeletal malignant neoplasms hospitalisation rates and key variables

\begin{tabular}{|c|c|c|c|c|c|c|c|c|c|c|c|c|c|c|c|}
\hline & SES & MUS & HFR & ALC & COD & FRV & SUG & OCA & HYP & OBE & REN & CAN & DSP & ART & OST \\
\hline SES & 1.00 & & & & & & & & & & & & & & \\
\hline MUS & $-0.28 *$ & 1.00 & & & & & & & & & & & & & \\
\hline HFR & $-0.36 * *$ & $0.35 * *$ & 1.00 & & & & & & & & & & & & \\
\hline ALC & -0.07 & $0.34 * *$ & 0.18 & 1.00 & & & & & & & & & & & \\
\hline COD & $-0.54 * *$ & $0.56 * *$ & $0.57 * *$ & $0.39 * *$ & 1.00 & & & & & & & & & & \\
\hline FRV & $-0.44 * *$ & $0.24 *$ & 0.04 & 0.07 & $.26^{*}$ & 1.00 & & & & & & & & & \\
\hline SUG & $-0.57 * *$ & $0.33 * *$ & $0.30 * *$ & 0.14 & $0.55^{* *}$ & $0.50 * *$ & 1.00 & & & & & & & & \\
\hline HYP & $-0.54 * *$ & $0.25 *$ & 0.21 & 0.04 & $0.45 *$ & $0.36 * *$ & $0.64 * *$ & $0.47 * *$ & 1.00 & & & & & & \\
\hline OBE & $-0.62 * *$ & $0.23 *$ & 0.20 & 0.01 & $0.44^{* *}$ & $0.59 * *$ & $0.72 * *$ & $0.50 * *$ & $0.69 * *$ & 1.00 & & & & & \\
\hline REN & $-0.39 * *$ & $0.33^{* *}$ & $0.54^{* *}$ & 0.20 & $0.51^{* *}$ & 0.08 & 0.17 & $0.23 *$ & 0.21 & 0.18 & 1.00 & & & & \\
\hline CAN & 0.02 & $0.27 *$ & 0.12 & $0.24 *$ & $0.28 *$ & -0.03 & 0.13 & 0.21 & 0.17 & 0.05 & 0.21 & 1.00 & & & \\
\hline DSP & $-0.89 * *$ & $0.32 * *$ & $0.38 * *$ & 0.20 & $0.55^{* *}$ & $0.52 * *$ & $0.57 * *$ & $0.52 * *$ & $0.504^{* *}$ & $0.60 * *$ & $0.32 * *$ & 0.07 & 1.00 & & \\
\hline ART & $-0.44 * *$ & $0.239 *$ & 0.19 & $0.24 *$ & $0.37 * *$ & $0.37 * *$ & $0.49 * *$ & $0.54 * *$ & $0.45^{* *}$ & $0.62 * *$ & 0.12 & 0.18 & $0.54^{* *}$ & 1.00 & \\
\hline OST & $-0.30 * *$ & -0.10 & 0.08 & $0.25 *$ & 0.11 & -0.04 & 0.01 & -0.07 & 0.18 & 0.21 & 0.14 & -0.06 & 0.21 & 0.21 & 1.00 \\
\hline
\end{tabular}

Note. ${ }^{* *}$ Correlation is significant at the 0.01 level (2-tailed); *correlation is significant at the 0.05 level (2-tailed). SES=socioeconomic status; MUS=age-adjusted musculoskeletal malignant neoplasms admissions per 10,000 population; HRF=age-adjusted heart failure admissions per 10,000 population; ALCO=prevalence (\%) of alcohol consumption at risky or high risk level based on National Health and Medical Research Council guidelines; COD=age-adjusted chronic obstructive pulmonary disease admissions per 10,000 population; FRV= compliance (\%) with neither fruit and vegetable consumption guidelines; SUG=prevalence (\%) of sugar-sweetened soft drinks; OCA=proportion of the population undertaking mostly heavy labour or physically demanding activity; HYP=prevalence (\%) of hypertension; OBE=prevalence (\%) of overweight and obesity; REN=age-adjusted renal failure admissions per 10,000 population; CAN=prevalence (\%) of cancer; DSP=proportion of the population on Disability Support Pension; ART=prevalence (\%) of arthritis; and OST=prevalence (\%) of osteoporosis. Data for ALC, FRV, SUG, OCA, HYP, OBE, CAN, ART and OST was taken from Victorian Population Health Survey 2011-12, Department of Health, Victoria. DSP data was taken from the Commonwealth Department of Human Services.

The findings regarding readmissions are consistent with other investigations. In the United States, Weeks et al. ${ }^{[1]}$ found a $13.9 \%$ 30-day readmission rate for musculoskeletal system among older veterans. Among 432 spinal cord injury patients in a Sydney hospital, MSC were the fourth leading cause of 30-day readmission $(8 \%)$. $^{[2]}$

The direct correlation between MMN admissions and DSP is unsurprising; arthritis is the leading cause of disability. ${ }^{[3]}$ Doctor-diagnosed arthritis prevalence is estimated ${ }^{[13]}$ to increase by $40 \%$ to nearly 67 million persons by 2030 in the United States. Three out of four Australians with arthritis report at least one other chronic condition, including cardiovascular diseases and obesity. In Australia, arthritis and other musculoskeletal diseases' healthcare expenditure was $\$ 5.7$ billion (in 2008-09), with half (54\%) of this for hos- pital admitted patient services. In the United States, MSC accounts for more disability and costs more to the healthcare system than any other condition. ${ }^{[14]}$ The United Nations' Bone and Joint Decade 2000-2010 recognises the need to address MSC.

The strengths of this study include the use of hospital admissions data and the large number of cases $(2,605)$. Most investigations exploring the relationship between socioeconomic status and musculoskeletal conditions are based on self-reported surveys, which may not capture the full severity of the disease in the population. Admissions data are useful for identifying variations in access to healthcare, populations with higher-than-average admission rates and health outcomes. The paper also shows significant associations between MNN and several conditions (see Table 1). One lim- 
itation is that the data does not reflect the general population as it excludes non-hospitalised cases. Hospital admissions data measures the episodes of care, and not the frequency of a given condition in the community. Another limitation is that using data for one year may not be representative of the pattern for longer time periods.

\section{Conclusion}

In summary, a strong association exits between community socioeconomic status and hospitalisation for musculoskeletal disorders. The healthcare costs of this condition are likely to increase with population ageing. Further analysis is required for effective intervention.

\section{REFERENCES}

[1] Weeks WB, Lee RE, Wallace AE, et al. Do older rural and urban veterans experience different rates of unplanned readmission to VA and non-VA Hospitals? The Journal of Rural Health. 2009; 25(1): 62-69. PMid:19166563. http://dx.doi.org/10.1111/j.1748-0361. 2009.00200.x

[2] Middleton JW, Lim K, Taylor L, et al. Patterns of morbidity and rehospitalisation following spinal cord injury. Spinal Cord. 2004; 42 : 359-367. PMid:15007376. http://dx.doi.org/10.1038/sj .sc .3101601

[3] Haralson RH, Zuckerman JD. Prevalence, health care expenditures, and orthopaedic surgery workforce and musculoskeletal conditions. Journal of the American Medical Association. 2009; 302(14): 158687. PMid:19826031. http://dx.doi.org/10.1001/jama. 2009 .1489

[4] Hannan MT, Anderson JJ, Pincus T, et al. Educational attainment and osteoarthritis: differential associations with radiographic changes and symptoms reporting. Journal of Clinical Epidemiology. 1992; 45(2): 139-147. http://dx.doi.org/10.1016/0895-4356(92 ) $90006-9$

[5] Cleveland RJ, Luong MN, Knight JB, et al. Independent associations of socioeconomic factors with disability and pain in adults with knee osteoarthritis. BMC Musculoskeletal Disorders. 2013; 14(297): 2474-14.

[6] Callahan LF, Cleveland RJ, Shreffler J, et al. Associations of educational attainment, occupation and community poverty with knee osteoarthritis in Johnston County (North Carolina) Osteoarthritis Project. Arthritis Research and Therapy. 2011; 13(5): R169.

[7] Juhakoski R, Tenhonen S, Anttonen T, et al. Factors affecting selfreported pain and physical function in patients with hip osteoarthritis. Archives of Physical Medicine and Rehabilitation. 2008; 89(6): 106673. PMid:18503801. http://dx.doi .org/10.1016/j.apmr. 20 07.10 .036
[8] Knight JB, Callahan LF, Luong MN, et al. The association of disability and pain with individual and community socioeconomic status in people with hip osteoarthritis. Open Rheumatology Journal. 2011; 5: 51-58. PMid:22046207. http://dx.doi.org/10.2174/18743 12901105010051

[9] Peters TJ, Sanders C, Dieppe P, et al. Factors associated with change in pain and disability over time: a community-based prospective observational study of hip and knee osteoarthritis. British Journal of General Practice. 2005; 55(512): 205-11.

[10] Martin KR, Shreffler J, Schoster B, et al. Associations of perceived neighbourhood environment on health status outcomes in persons with arthritis. Arthritis Care Research (Hoboken). 2010; 62(11): 1602-11. PMid:20521309. http://dx.doi.org/10.1002/acr. 2 0267

[11] Andersen S, Thygesen LC, Davidsen M, et al. Cumulative years in occupation and the risk of hip or knee osteoarthritis in men and women: a register-based follow-up study. Occupational and Environmental Medicine. 2012; 69(5): 325-30. PMid:22241844. http://dx.doi.org/10.1136/oemed-2011-100033

[12] Allen KD, Chen JC, Callahan LF, et al. Associations of occupational tasks with knee and hip osteoarthritis: the Johnston County Osteoarthritis Project. Journal of Rheumatology. 2010; 37(4): 842-850. PMid:20156951. http://dx.doi.org/10.3899/jrheum.0903 02

[13] Centres for Disease Control and Prevention. Prevalence of disabilities and associated health conditions among adults - United States, 1999. Morbidity and Mortality Weekly Report. 2001; 50(7): 120-125. PMid:11393491.

[14] Haralson RHH, Zuckerman JD. Prevalence, health care expenditures, and orthopaedic surgery workforce and musculoskeletal conditions Journal of the American Medical Association. 2009; 302(14): 15861587. PMid:19826031. http://dx.doi.org/10.1001/jama. 20 09.1489 